\title{
Serial Blood and Urine Drug Concentration Measurement in a Patient Withacute Intoxication Bytramadoland Zolpidem Resulting in Qt Prolongation: Case Report
}

\section{Bonggyu Lee}

Chungnam National University Hospital

Jungsoo Park

Chungnam National University Hospital

Suncheun Kim

National Forensic Service

Dongwoo Kim

National Forensic Service

Dongeun Park

National Forensic Service

Hyejin Chang

National Forensic Service

Yeonho You

Chungnam National University Hospital

Changshin Kang

Chungnam National University Hospital

Hongjoon Ahn

Chungnam National University Hospital

won joon JEONG ( $\square$ gardenjun@hanmail.net )

Chungnam National University Hospital https://orcid.org/0000-0002-6320-230X

\section{Case report}

Keywords: Zolpidem, Tramadol, QT prolongation, Blood concentration

Posted Date: June 19th, 2020

DOl: https://doi.org/10.21203/rs.3.rs-36399/v1

License: (c) (i) This work is licensed under a Creative Commons Attribution 4.0 International License. Read Full License 
Page $2 / 10$ 


\section{Abstract}

Background: QT prolongation is a well-known complication when tramadol or zolpidem is ingested in large amounts acutely. However, the blood drug concentration resulting in QT prolongation or tachyarrhythmia when tramadol and zolpidem are ingested simultaneously in large amounts has not yet been reported. We report a case of acute intoxication by tramadol and zolpidem resulting in QT prolongation in a patient in whomserial blood and urine tramadol and zolpidemconcentrationswere determined.

Case presentation:A 38-year-old male patient presented tothe emergency medical centrebecause ofpoisoning from $3 \mathrm{~g}$ of tramadol and $50 \mathrm{mg}$ of zolpidemat $3 \mathrm{~h}$ before hisemergency department(ED) visit.During supportive treatment, he developed QT prolongation without clinical manifestations. He was discharged five days after admission without any sequelae. We measured the blood and urine concentrations of tramadol and zolpidemat various time points, which revealed ablood tramadol concentration-dependent change in QTc intervals and increasing blood tramadol concentration at $8 \mathrm{~h}$ after the ED visit,with a sustainedlow zolpidem concentration.Tramadol and zolpidem are metabolized by the same enzyme, cytochrome P450 3A4. Therefore, competitive inhibition bya P450 3A4isoenzyme may lead to increases indrugtoxicity. The QT interval in patients acutely intoxicated bytramadol should be evaluated carefully, particularlywhen tramadol is co-ingested with other drugs.

Conclusions:Considering the half-life of tramadolor zolpidem and potential for continued absorption of drugs remaining in the gastrointestinal tract, it is necessary to observe patients viacardiac monitoring for more than 36 hafteracute intoxication. The blood concentration of tramadol may increaseand result in QT prolongationeven afterappropriate initial treatment.

\section{Background}

Tramadol and zolpidem are well-known analgesics and hypnotics widely used to treat pain or insomnia. Recently, cardiac safety concerns regarding administration of zolpidem have been raised by a case of long QT syndrome complicated by torsade de pointes tachyarrhythmia [1]. QT prolongation is a wellknown complication that occurs when tramadol is ingested in large amounts acutely. The toxic and lethal blood concentrations of tramadol and zolpidem have been reported in post-mortem cases. However, the blood drug concentration resulting in QT prolongation or tachyarrhythmia when tramadol and zolpidem are ingested simultaneously in large amounts has not been reported. Herein, we report a case of acute intoxication from these drugs resulting in QT prolongation in a patient by evaluating serial blood and urine concentrations of the drugs.

\section{Case Presentation}

A 38-year-old male presented to the emergency department (ED) with a chief complaint of acute intoxication. He reported that he had ingested 60 tablets of Tridolß (tramadol hydrochloride $50 \mathrm{mg}$, 
YUHAN, Seoul, South Korea) and 5 tablets of Zolpiram ${ }^{\circledR}$ (zolpidem tartrate $10 \mathrm{mg}$, Whan In Pharm, Seoul, South Korea) $4 \mathrm{~h}$ prior and had been treated for psychiatric disorders, including depression, anxiety, and insomnia, for many years. He had also been diagnosed with Wolff-Parkinson-White syndrome 6 years prior.

At the time of the visit, the patient scored 14 points (E3V5M6) on the Glasgow coma scale. His blood pressure was $152 / 105 \mathrm{mmHg}$, heart rate was 98 beats/min, breathing rate was 20 breaths/min, body temperature was $37.0^{\circ} \mathrm{C}$, and oxygen saturation was $95 \%$. Neurological examination revealed no abnormal cranial reflex or brainstem signs. The results of an arterial blood test showed respiratory acidosis and hypoxemia $\left(\mathrm{pH}, 7.37 ; \mathrm{pCO}_{2}\right.$ level, 52 mmHg; $\mathrm{pO}_{2}$ level, $73 \mathrm{mmHg} ; \mathrm{HCO}_{3}$ level, 27.6 mmHg; $\mathrm{O}_{2}$ saturation, 94\%); the complete blood cell count test and electrolyte examinations $(\mathrm{Na}, \mathrm{K}, \mathrm{Cl}, \mathrm{Mg})$ showed normal values. He had been administered gastric irrigation and activated charcoal for poisoning treatment. A baseline electrocardiogram (ECG) on admission showed sinus tachycardia with 117 beats/min and a corrected QT (QTc) interval of $530 \mathrm{~ms}$. The QRS interval was $98 \mathrm{~ms}$, although a suspicious delta wave in the upstroke to QRS and PR interval of 130 ms were observed (Fig. 1). At $8 \mathrm{~h}$ after admission (12 h after exposure), an ECG showed a PR interval of $102 \mathrm{~ms}$, QRS duration of $110 \mathrm{~ms}$ with a delta wave, and QTc of $543 \mathrm{~ms}$, indicating Wolff-Parkinson-White syndrome with QT prolongation (Fig. 2). The QTc interval decreased to $524 \mathrm{~ms}, 485 \mathrm{~ms}$ at $24 \mathrm{~h}, 36 \mathrm{~h}$ after exposure respectively (Fig. 3,4).

The patient was hospitalized in the intensive care unit for close cardiac monitoring. After informed consent was obtained, serial blood and urine samples were collected at 8- or 12-h intervals from the time of the ED visit and sent to the National Forensic Service of Korea for drug concentration analysis. Figure 5 shows the changes in the blood and urine concentrations of tramadol and zolpidem with the QTC interval change over time. Blood and urine concentrations of tramadol at the ED visit were 2.87 and $28.04 \mathrm{mg} / \mathrm{L}$, respectively, and those of zolpidem were $0.02 \mathrm{mg} / \mathrm{L}$ and below the quantitative limit, respectively. Eight hours after the ED visit, the blood and urine concentrations of tramadol sharply increased to 4.03 and $96.86 \mathrm{mg} / \mathrm{L}$, respectively. In contrast, the blood concentration of zolpidem decreased to $0.001 \mathrm{mg} / \mathrm{L}$. The measured concentrations of tramadol peaked at $8 \mathrm{~h}$ after the ED visit and then began decreasing linearly over time. The change in the QTc interval was consistent with the change in the blood levels of tramadol. The patient was discharged without any complications after five days of hospitalization.

\section{Discussion And Conclusions}

This is the first report describing the determination of blood and urine concentrations of tramadol and zolpidem at regular time intervals in a patient. Tramadol, a synthetic opiate, is used in pain treatment. It is metabolized by the cytochrome P450 (CYP) enzymes CYP2D6 and CYP3A4, and its elimination half-life is known to be $9 \mathrm{~h}$ [2]. Several cases of tramadol poisoning have been reported, including lethal intoxications [3, 4], and the toxic concentration is known to be $>2 \mathrm{mg} / \mathrm{L}$ [5]. The blood drug concentration was reported to be $7.7 \mathrm{mg} / \mathrm{L}$ in one post-mortem case from acute tramadol poisoning death and $48.34 \mathrm{mg} / \mathrm{L}$ in other cases [6]. A previous study in 2016 reported prolonged QTc intervals in $18.4 \%$ of 
1402 patients with tramadol poisoning [7]. In another study, Keller et al. reported that tramadol produced QTc prolongation that was well-correlated with plasma drug concentrations [8]. However, unlike the study by Keller et al., which was conducted while patients took prescriptions normally, this case involved a patient with acute overdose poisoning from an estimated total of $3 \mathrm{~g}$ of tramadol and $50 \mathrm{mg}$ of zolpidem. In the present case, a serial blood tramadol concentration-dependent change in the QTc interval was observed, which is consistent with the findings of Keller et al. The patient's blood concentration and QTC interval simultaneously increased in the $8 \mathrm{~h}$ after the ED visit despite general treatment of the patient for acute poisoning. This suggests the potential for continued absorption of drug components remaining in the gastrointestinal tract, as the time to peak concentration is independent of the dose and depends only on the rates of absorption and elimination [9]. Zolpidem is also mainly metabolized by cytochrome P450 3A4 [10] and may have a synergistic effect in tramadol poisoning because it undergoes metabolism via the same pathway, and this interaction can enhance QT prolongation by decreasing drug clearance. However, in this case, zolpidem levels remained below the therapeutic concentration; thus, the effect of acute ingestion of zolpidem was minimal.

In conclusion, considering the half-life of tramadol or zolpidem and potential for continued absorption of drugs remaining in the gastrointestinal tract, it is necessary to observe patients via cardiac monitoring for more than $36 \mathrm{~h}$ in acute intoxication. The blood concentration of tramadol may increase and result in QT prolongation even after appropriate initial treatment, as observed in this case.

\section{List Of Abbreviations}

ED, emergency department; ECG, electrocardiogram; QTc, corrected QT

\section{Declarations}

\section{Ethics approval and consent to participate}

IRB No. CNUH 2020-06-073

\section{Consent for publication}

Written informed consent was obtained from the patient for publication of this case report and $x$ accompanying images. A copy of the written consent is available for review by the Editors-in-Chief of this journal

\section{Availability of data and materials}

Not applicable 


\section{Competing interests}

The authors declare that they have no competing interests

\section{Funding}

Not applicable

\section{Authors' contributions}

WJ conceived the idea for the manuscript and supervisedentire writing process. BL and JP helped to write the manuscript. SK, DK, DP, and HC analysed and interpreted data of the sampled blood and urine by liquid chromatography. $\mathrm{CK}$ and $\mathrm{HJ}$ treated patients in the intensive care unit under the supervision of $\mathrm{YY}$, the ICU specialist. All authors read and approved the final manuscript

\section{Acknowledgements}

We would like to express our deepest gratitude to colleagues working in the Daejeon Institute of National Forensic Service for their comments on this manuscript.

\section{References}

1. Ahn HJ, Jeong WJ, Kim KJ, Kim SC, Kim DW, Chang HJ, et al. Serial plasma and urine measurements of a patient with acute intoxication of zolpidem and flunitrazepam resulting in QT prolongation and ventricular tachycardia. Clinical Toxicology 2019:1-3.

2. Miotto K, Cho AK, Khalil MA, Blanco K, Sasaki JD, Rawson R. Trends in Tramadol: Pharmacology, Metabolism, and Misuse. Anesth Analg. 2017;124:44-51.

3. Randall C, Crane J. Tramadol deaths in Northern Ireland: a review of cases from 1996 to 2012. J Forensic Leg Med. 2014;23:32-6.

4. Shadnia S, Soltaninejad K, Heydari K, Sasanian G, Abdollahi M. Tramadol intoxication: a review of 114 cases. Hum Exp Toxicol. 2008;27:201-5.

5. Clarkson JE, Lacy JM, Fligner CL, Thiersch N, Howard J, Harruff RC, et al. Tramadol (Ultram) concentrations in death investigation and impaired driving cases and their significance. J Forensic Sci. 2004;49:1101-5.

6. De Backer B, Renardy F, Denooz R, Charlier C. Quantification in Postmortem Blood and Identification in Urine of Tramadol and Its Two Main Metabolites in Two Cases of Lethal Tramadol Intoxication. J Anal Toxicol. 2010;34:599-604. 
7. Alizadeh Ghamsari A, Dadpour B, Najari F. Frequency of Electrocardiographic Abnormalities in Tramadol Poisoned Patients; a Brief Report. Emerg (Tehran). 2016;4:151-4.

8. Keller A, Etchegoyen GCV, Fernandez M, Olivera NM, Quiroga NN, Belloso PH. W, et al. Tramadol Induced QTc-Interval Prolongation: Prevalence, Clinical Factors and Correlation to Plasma Concentrations. CDS. 2016;11:206-14.

9. Goldfrank LR, Hoffman RS, Howland MA, Lewin NA, Nelson L. Goldfrank's toxicologic emergencies. 10th ed. New York: McGraw-Hill Education LLC.; 2015.

10. von Moltke LL, Weemhoff JL, Perloff MD, Hesse LM, Harmatz JS, Roth-Schechter BF, et al. Effect of zolpidem on human cytochrome P450 activity, and on transport mediated by P-glycoprotein.

Biopharm Drug Dispos. 2002;23:361-7.

\section{Figures}

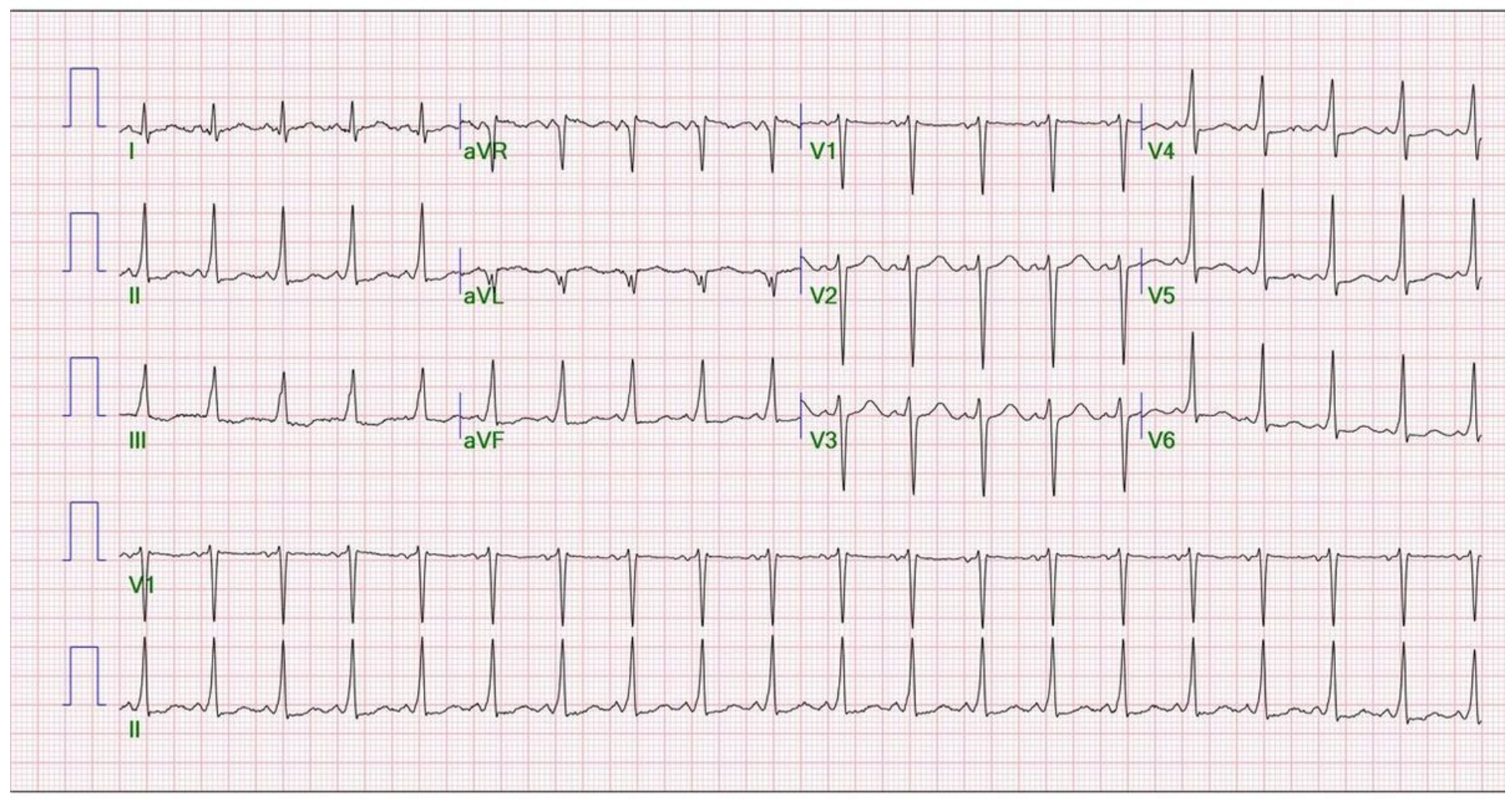

Figure 1

ECGat4 hafter exposure, showing QTc prolongation of 530ms. 
Drug concentration of blood, urine and QT interval over time

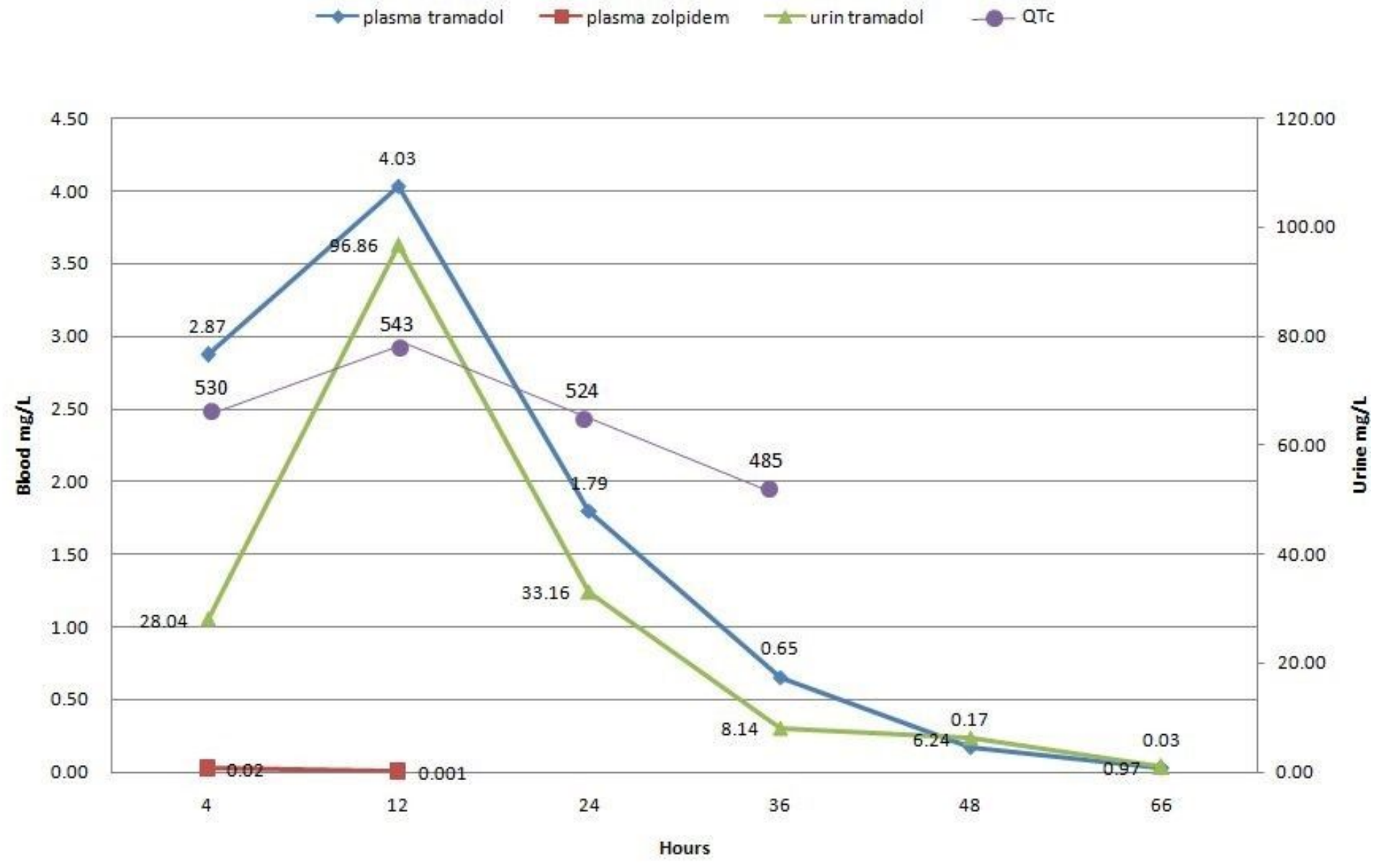

Figure 2

ECG at 12 hafter exposure, showing QTc prolongation of 543ms. 
几

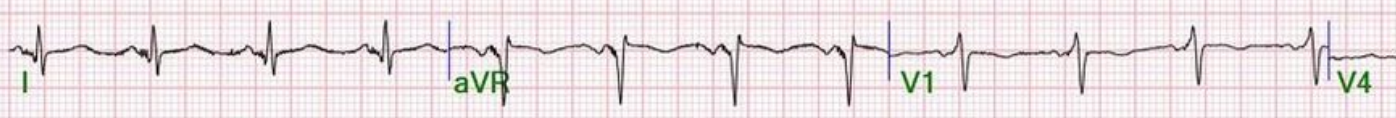

$\Pi d_{11} L d v_{v 2}$

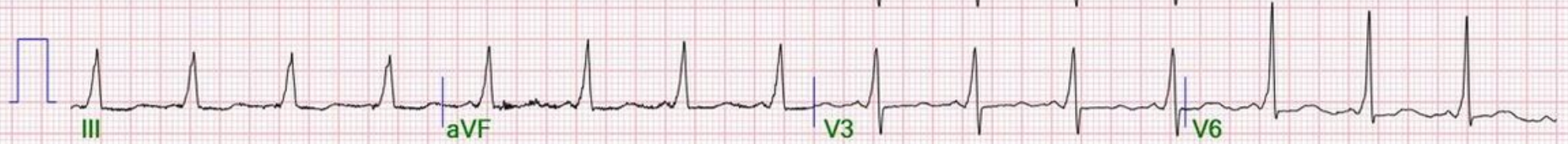

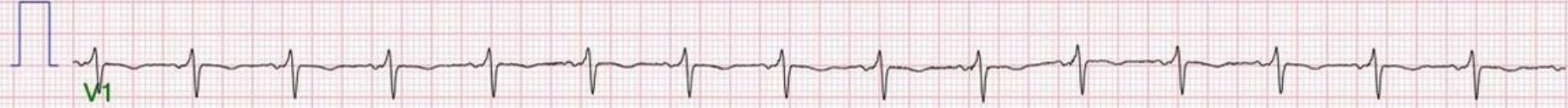

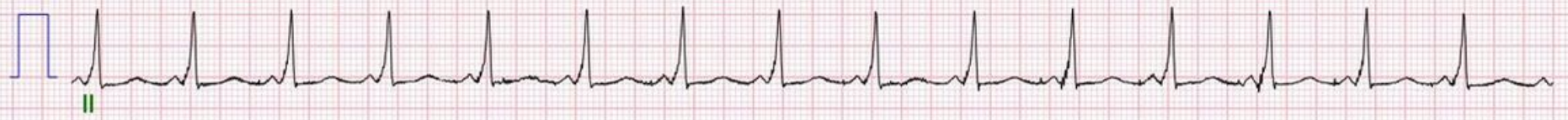

Figure 3

ECG at 24 hafter exposure, showing QTc prolongation of $524 \mathrm{~ms}$.

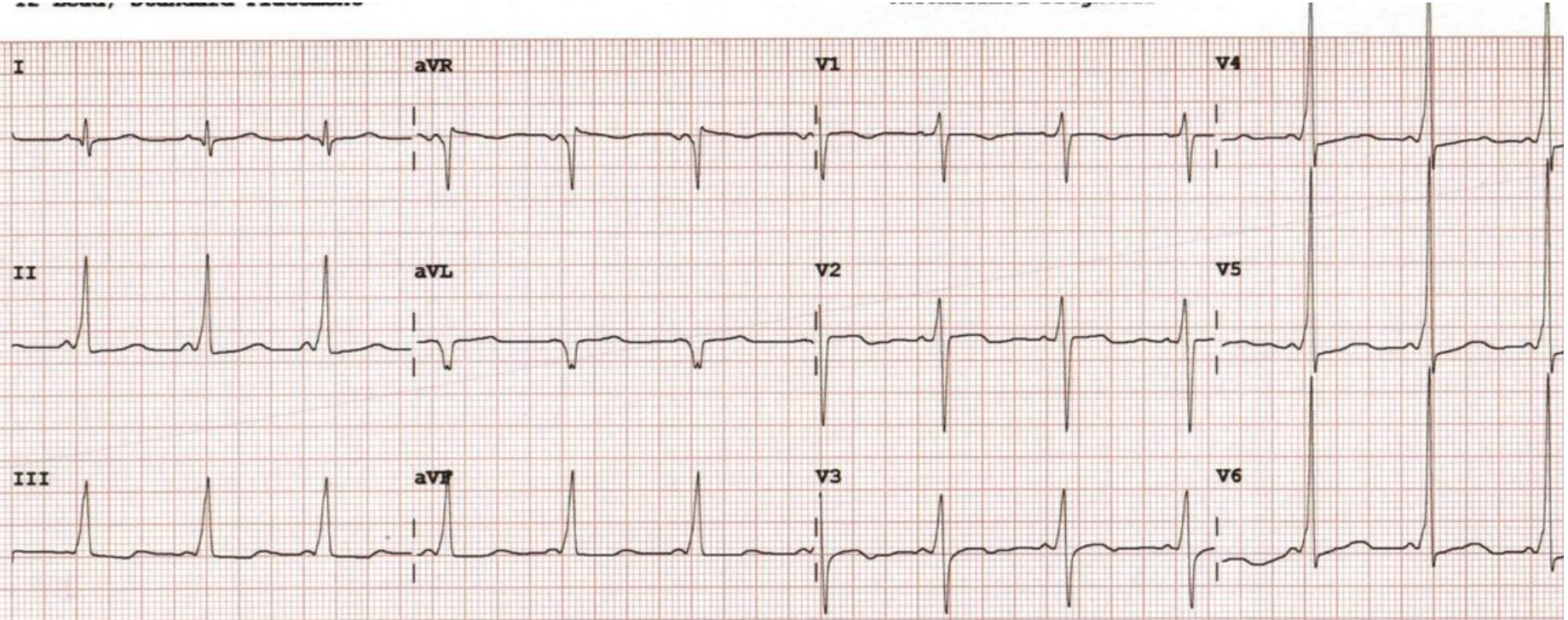

II

\section{Figure 4}

ECG at 36 hafter exposure, showing QTc of $485 \mathrm{~ms}$. 


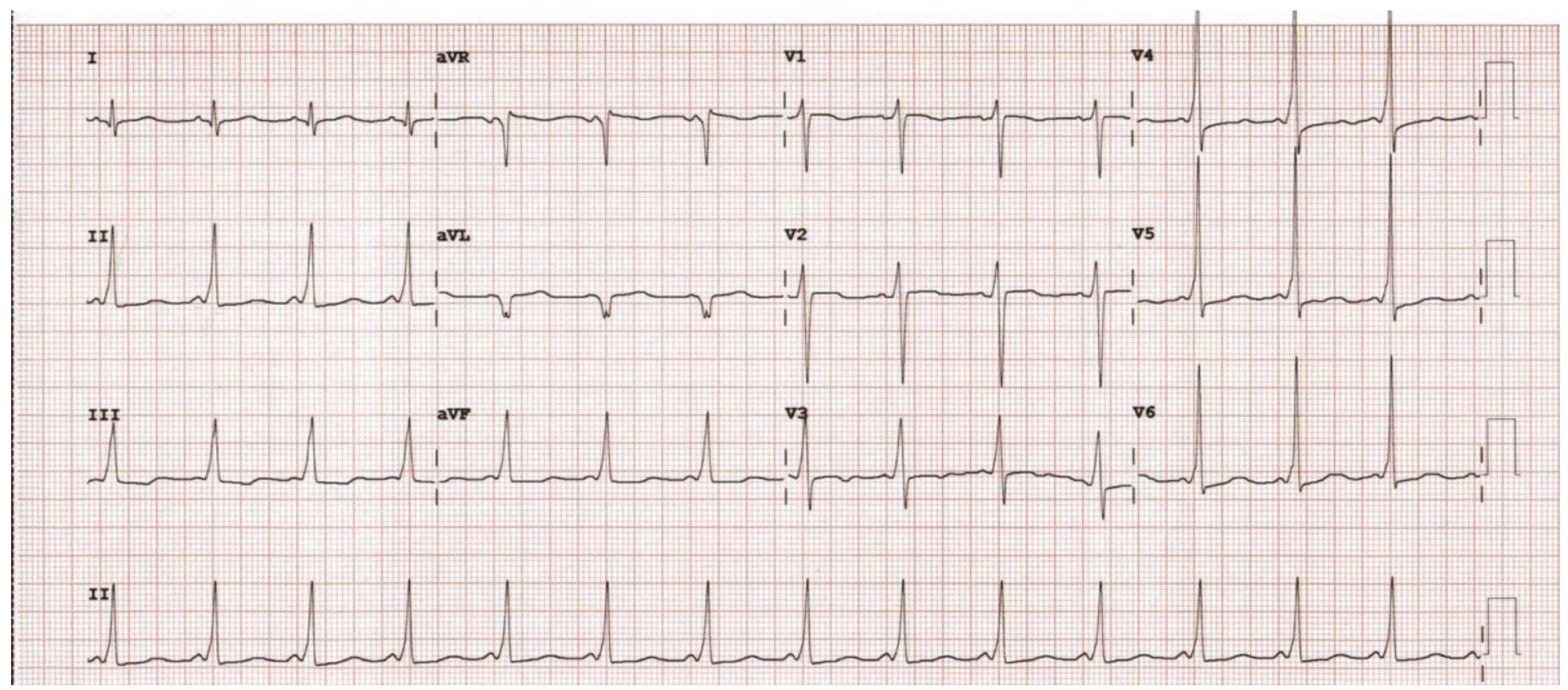

Figure 5

QT intervals and drug concentrations in blood and urine over time

\section{Supplementary Files}

This is a list of supplementary files associated with this preprint. Click to download.

- renamed95853.doc 